\title{
Yannick Fer, Gwendoline Malogne-Fer (éds.), Le protestantisme évangélique à l'épreuve des cultures
}

Paris, L'Harmattan, coll. « Anthropologie critique », 2013,162 p.

\section{Maixant Mebiame Zomo}

\section{(2) OpenEdition \\ Journals}

\section{Édition électronique}

URL : http://journals.openedition.org/assr/26409

DOI : $10.4000 /$ assr.26409

ISSN : $1777-5825$

\section{Éditeur}

Éditions de l'EHESS

Édition imprimée

Date de publication : 31 décembre 2014

Pagination : 185

ISBN : 978-2-7132-2467-6

ISSN : 0335-5985

\section{Référence électronique}

Maixant Mebiame Zomo, « Yannick Fer, Gwendoline Malogne-Fer (éds.), Le protestantisme

évangélique à l'épreuve des cultures », Archives de sciences sociales des religions [En ligne], 168 | 2014, mis en ligne le 17 avril 2015, consulté le 22 septembre 2020. URL : http://journals.openedition.org/ assr/26409; DOI : https://doi.org/10.4000/assr.26409 


\section{Yannick Fer, Gwendoline Malogne- Fer (éds.), Le protestantisme évangélique à l'épreuve des cultures}

Paris, L'Harmattan, coll. « Anthropologie critique », 2013,162 p.

Maixant Mebiame Zomo

\section{RÉFÉRENCE}

Yannick Fer, Gwendoline Malogne-Fer (éds.), Le protestantisme évangélique à l'épreuve des cultures, Paris, L'Harmattan, coll. « Anthropologie critique », 2013,162 p. 
Ce collectif présenté par Yannick Fer et Gwendoline Malogne-Fer, deux chercheurs connus pour leurs recherches sur le terrain océanien (Le pentecôtisme en Polynésie française, 2005; L'offensive évangélique. Voyage au coeur des réseaux militants de Jeunesse en Mission, 2010 ; etc.), s'inscrit au cœur des préoccupations actuelles de l'anthropologie et de la sociologie du christianisme contemporain. Ces différentes contributions sont issues d'une journée d'étude organisée le 19 octobre 2011 à l'Université Toulouse II Le Mirail. Le thème central de l'ouvrage concerne les modalités d'articulation entre christianismes et altérité culturelle. Si l'interrogation est ancienne et a suscité de nombreux écrits et réflexions chez les missionnaires et les théologiens protestants et catholiques, ces

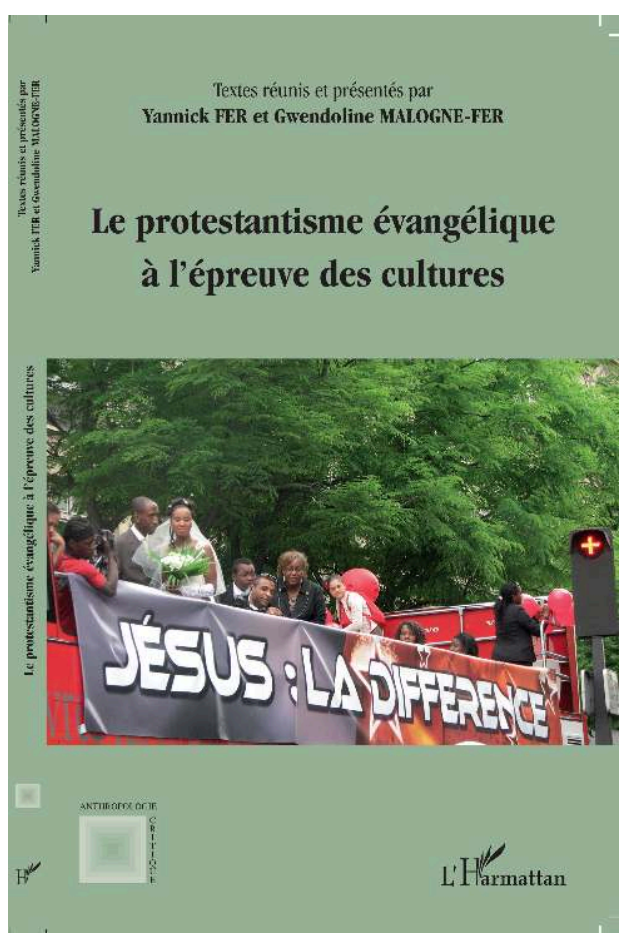
questionnements revêtent aujourd'hui une acuité particulière sous l'effet de l'intensification des migrations internationales et des recompositions des dynamiques missionnaires, qui s'appuient sur une remise en cause d'un partage Nord/Sud en matière de compétences missionnaires.

2 Les riches exemples ethnographiques formant le corps de ce collectif permettent d'explorer les contextes sociaux illustrant comment ces cultures reçoivent ces idiomes religieux ou comment ces derniers se positionnent par rapport aux cultures qui les accueillent. Les textes, à l'exception de celui de Valérie Aubourg, étudient le protestantisme en milieu urbain, dans les grandes villes (Nantes et Rennes) et surtout dans les grandes métropoles (Le Caire, Londres et Paris), ces capitales politiques et économiques constituant un lieu privilégié de brassage culturel et religieux.

Hormis l'introduction de Gwendoline Malogne-Fer qui discute les questions d'ordres théorique et méthodologique liés aux objets approchés, les six autres contributions qui constituent cet ouvrage peuvent se répartir en deux axes. Le premier axe de réflexion à travers les articles de Boutter, Picard, Wood et Eade s'intéresse aux différentes manières dont les acteurs du protestantisme partageant le même espace urbain nouent des relations ponctuelles ou durables et interagissent avec les autorités municipales. C'est dire que ce monde urbain est véritablement un milieu concurrentiel, voire conflictuel et "compétitif» pour reprendre l'expression de Stolz, Favre et al. (Le phénomène évangélique, Analyse d'un milieu compétitif, Labor et Fides, 2013). Comme le soulignait Georg Simmel (Le conflit, Circé, 2003), la concurrence s'exerce par l'entremise d'un tiers - ici, le fidèle - qu'il s'agit de séduire, d'attirer, de conserver en usant de ses propres atouts. Le conflit implique en revanche une confrontation directe entre acteurs religieux car il est une lutte pour s'approprier un objet que l'autre possède. De cette concurrence, il résulte des interactions renouvelées entre acteurs et religions. La concurrence et le conflit devenant ainsi des modes de relation observables entre les acteurs religieux. Comme le soulignent aussi certains travaux sur le terrain africain, 
«les emprunts, les mimétismes, les évolutions convergentes sont également notables [dans le contexte urbain] conférant aux scènes religieuses locales une diversité et une richesse " (Maud et Mayrarque, «Introduction au thème. Le religieux dans la pluralisation contemporaine. Éclatement et concurrence », Politique africaine, $\mathrm{n}^{\circ} 123$, 2011, p. 6).

4 Le second axe dans lequel s'inscrivent les articles de Valérie Aubourg, Géraldine Mossière et Bernard Coyault étudie davantage les migrations, les mobilités et les circulations religieuses qui sont au cœur des transformations du paysage protestant contemporain. Des circulations entre églises protestantes évangéliques et charismatiques, mais aussi entre milieux charismatiques catholiques et protestants s'inscrivent dans un champ protestant marqué, depuis les années 1980-1990, par ce qu'on appelle les Églises charismatiques de la «troisième vague ». Les circulations se donnent à voir à travers les itinéraires des pasteurs africains qui s'appuient sur leur parcours migratoire pour légitimer de nouveaux ministères. Les expériences migratoires se transforment ainsi en ressources professionnelles. Mais dans le même temps, les pratiques religieuses des fidèles qui en fréquentant simultanément ou en alternance différents lieux de culte, tentent de mettre à bonne distance l'autorité pastorale et le contrôle paroissial. Ce deuxième axe vient à nouveau nourrir le débat sur une problématique qui a intéressé de nombreux chercheurs et dont certains contributeurs de cet ouvrage ont participé (voir Sandra Fancello et André Mary, "Christianismes du Sud à l'épreuve de l'Europe", Archives de Sciences Sociales des Religions, $\mathrm{n}^{\circ}$ 143, 2008 et Chrétiens africains en Europe. Prophétismes, pentecôtismes et politique des nations, Paris, Karthala, 2010). Bien que l'on puisse regretter l'absence de véritable début autour des enjeux méthodologiques de nombre d'enquêtes de terrain ici relatées, la richesse et la diversité de ces dernières font tout l'intérêt de ce collectif. 